\title{
ВЛИЯНИЕ ЗНАЧИМЫХ ЖИЗНЕННЫХ СОБЫТИЙ ВЗАИМОДЕЙСТВИЯ С ДРУГИМИ НА ВОЗНИКНОВЕНИЕ КРИЗИСА СИСТЕМЫ ОТНОШЕНИЙ ЛИЧНОСТИ
}

Альперович В.Д.

В данной статье рассматривается такой феномен, как «кризис системы отношений». Выделены значимые жизненные события и ситуачии взаимодействия, обусловливающие различные уровни рассогласования модальностей отношений к себе, Другим, ожидаемых отношений.

Ключевые слова: кризис системы отношений, отношение к себе, отношение Других, ожидаемое отношение Других, значимое жизненное событие, ситуаиии взаимодействия.

Переломные периоды жизненного пути человека в отечественной психологии исследуются в связи со значимыми жизненными событиями. Традиции изучения жизненного события опираются на его понимание С.Л. Рубинштейном как «узлового момента и поворотного этапа» жизненного пути, определяющего его дальнейшее течение и развитие личности [13]. Как указывал С.Л. Рубинштейн, то, что составляет содержание события: действия личности по отношению к другим людям (поступки) и действия других людей по отношению к личности, обусловливая развитие рефлексии, прерывающей «непрерывный процесс жизни», выводят человека «за пределы самого себя» и наличной ситуации. «Выход за пределы самого себя» есть способ бытия человека как субъекта жизни, определяемого его отношением к себе, неразрывно связанным с отношением Других к данной личности, отношением к жизни, миру и Другим [12]. Отечественная психология жизненного пути, развивая взгляды С.Л. Рубинштейна, постулирует зависимость личностных изменений от «разрывающих» привычные связи жизненных событий и ситуаций, которые сама личность оценивает в качестве значимых, переломных $[1,2,3,9,10,14]$.

В исследованиях отечественных психологов $[5,6,11]$ подчеркивается влияние жизненных событий на динамику системы отношений личности. Исходя из этих работ и многих других $[4,7,8,15]$, в нашем исследовании феномен «кризис системы отношений» трактуется как одна из форм взаимодействия между различными видами отношений, образующих систему, для которой является характерным наличие неразрешимых на данном этапе жизненного пути воспринимаемых противоречий между сложившимися значимыми отношениями (к себе, к Другим и ожидаемого от Других) и развивающимися (формирующимися) значимыми отношениями, имеющими бытийный смысл для личности. Такое понимание феномена «кризис системы отношений» позволяет высказать предположение, что жизненные события обусловливают меру согласования/ рассогласования видов отношений, образующих систему отношений, 
и выступают в качестве фактора рассогласованности модальностей различных видов отношений, соответствующих кризисной, предкризисной, бескризисной системам отношений.

Целями данного исследования являются изучение влияния значимых жизненных событий на уровень рассогласования модальностей различных видов отношений и определение меры рассогласования, свидетельствующего о кризисе системы отношений.

Для выявления меры соответствия/рассогласования между отношениями к себе, к Другим и ожидаемого отношения Других использовалась методика «Диагностики межличностных отношений» Т. Лири. Для определения значимых жизненных событий в различных сферах взаимодействия применялась разработанная нами на основе метода «Незаконченные предложения» методика «Значимые жизненные события в период взрослости». Эмпирический объект исследования составили 204 человека в возрасте от 32 до 45 лет (95 мужчин, 109 женщин - служащие предприятий г. Ростова-на-Дону).

На основе теоретического анализа проблемы отношений нами были выделены следующие критерии уровней соответствия/рассогласования системы отношений:

1) показатели кризиса системы отношений:

а) высокая степень выраженности отношений модальностей «авторитарные», «эгоистические», «подчиняемые», «зависимые» (количество принятых респондентом характеристик отношений любой из этих модальностей должно быть $\geq 68,7$ \% от количества характеристик отношений каждой модальности, заданных Т. Лири),

б) небольшое количество соответствующих друг другу характеристик, приписываемых респондентом отношениям данных модальностей (количество этих характеристик должно быть $\leq 12,5$ \% от количества характеристик отношений каждой модальности, заданных Т. Лири),

в) значительное превосходство (в 2 раза и более) объема не соответствующих друг другу характеристик отношений над объемом соответствующих друг другу характеристик отношений в данных модальностях и в модальностях «агрессивные», «подозрительные»;

2) показатели предкризисной системы отношений:

а) средняя степень выраженности отношений модальностей «авторитарные», «эгоистические», «подчиняемые», «зависимые» (количество принятых респондентом характеристик отношений любой из этих модальностей должно быть равным 56,2 \% от количества характеристик отношений каждой модальности, заданных Т. Лири),

б) незначительное количество соответствующих друг другу характеристик, приписываемых респондентом отношениям данных модальностей (количество этих характеристик должно быть равным 25 \% от количества характеристик отношений каждой модальности, заданных Т. Лири),

в) равенство объемов не соответствующих друг другу характеристик отношений и соответствующих друг другу характеристик отношений в данных модальностях и в модальностях «агрессивные», «подозрительные»; 
3) показатели бескризисной системы отношений:

а) низкая степень выраженности отношений модальностей «авторитарные», «эгоистические», «подчиняемые», «зависимые» (количество принятых респондентом характеристик отношений любой из этих модальностей должно быть равным 37,5-43,7 \% от количества характеристик отношений каждой модальности, заданных Т. Лири),

б) большое количество соответствующих друг другу характеристик, приписываемых респондентом отношениям данных модальностей (количество этих характеристик должно быть $\geq 37,5$ \% от количества характеристик отношений каждой модальности, заданных Т. Лири),

в) значительное (в 2 раза и более) превосходство объема соответствующих друг другу характеристик отношений над объемом не соответствующих друг другу характеристик отношений в данных модальностях и в модальностях «агрессивные», «подозрительные».

Значимые отношения респондентов модальностей «авторитарные», «эгоистические», «подчиняемые» и «зависимые», выделенные на основе предшествующего теоретического анализа социально-психологических особенностей субъектов общения, переживающих и не переживающих кризис системы отношений, рассматривались с позиции отношения к себе, отношения Других и ожидаемого отношения Других.

Данные обрабатывались посредством формального (количественного) сравнительного анализа объема соответствующих и не соответствующих друг другу характеристик, приписываемых отношениям в каждой модальности каждым респондентом. Достоверность полученных результатов и основанных на них выводов обеспечивалась использованием кластерного анализа и стандартного программного пакета статистической обработки данных «SPSS 13.0» для Windows.

Полученные данные позволили разделить респондентов на 3 группы.

Особенности системы отношений респондентов первой группы (29 мужчин, 22 женщины в возрасте 32-45 лет) соответствуют выделенным нами критериям кризисной системы отношений и обнаруживают выраженное противоречие отношения к себе и ожидаемого отношения Других отношению Других по критерию их модальностей.

Особенности системы отношений респондентов второй группы (29 мужчин, 23 женщины в возрасте 32-45 лет) соответствуют выделенными нами критериям предкризисной системы отношений и обнаруживают менее выраженное противоречие отношения к себе и ожидаемого отношения Других отношению Других по критерию их модальностей.

Особенности системы отношений респондентов третьей группы (37 мужчин, 64 женщины в возрасте 32-45 лет) соответствуют выделенным нами критериям бескризисной системы отношений и обнаруживают согласованность отношения к себе, ожидаемого отношения Других и отношения Других по их модальностям.

Респонденты с кризисной системой отношений и респонденты с предкризисной системой отношений, описывая значимые, переломные события и ситуации, 
акцентируют события и ситуации, обусловливающие противоречия, рассогласования отношения Других и ожидаемого отношения Других: предательство значимых других (как обман доверия, разглашение конфиденциальной информации друзьями, коллегами, измена возлюбленных, супругов), разочарование в них, развод, изменение отношений с ними, смены места работы и/или сферы деятельности.

Респонденты с бескризисной системой отношений акцентируют события и ситуации, непосредственно не обусловливающие противоречия, рассогласования отношения Других и ожидаемого отношения Других (в т. ч. переезд в другой город, поступление в институт и его окончание, получение диплома, брак, рождение детей), обозначающие в социально-психологическом смысле связанную с ними и детерминированную социальными сценариями жизненного пути человека динамику социальной идентичности респондентов.

Полученные данные свидетельствуют о том, что жизненные события следующих типов, различающихся между собой: 1) события - отрицательные поступки значимого Другого (события отрицательного поведения Другого); 2) события - изменения социального статуса субъекта, - обусловливают различные уровни рассогласования модальностей отношений, образующих систему отношений личности.

Полученные данные подтверждают выдвинутую нами гипотезу о том, что жизненные события выступают в качестве фактора рассогласованности модальностей различных видов отношений, соответствующих кризисной, предкризисной, бескризисной системам отношений.

\section{Литература}

1. Абульханова-Славская К.А. Стратегия жизни. - М.: Мысль, 1991. - 299 с.

2. Анцыферова Л.И. Личность в трудных жизненных условиях: переосмысливание, преобразование ситуаций и психологическая защита // Психологический журнал. - Т. 15. - № 1. - 1994. - С. 3-18.

3. Бодалев А.А. О событиях в жизни человека и человеке как событии // Мир психологии. - № 4(24). - 2000. - С. 66-70.

4. Братусь Б.С. К проблеме развития личности в зрелом возрасте // Вестн. Моск. ун-та. - Сер. 14. Психология. - № 2. - 1980. - С. 3-12.

5. Демин А.Н. Особенности переживания личностью кризисов своей занятости // Вопросы психологии. - № 3. - 2006. - С. 87-96.

6. Джанерьян С.Т. Потеря работы: жизненное событие и ситуация // Психол. вестн. РГУ. - Вып. 1. - Ч. 2. - 1996. - С. 272-282.

7. Емельянова Е.В. Кризис в созависимых отношениях. Принципы и алгоритмы консультирования. - СПб.: Речь, 2008. - 368 с.

8. Журавлева Н.А. Динамика ценностных ориентаций личности в условиях социально-экономических изменений. Дис... канд. психол. н. - М., 2002.

9. Карцева Т.Б. Личностные изменения в ситуациях жизненных перемен // Психологический журнал. - Т. 9. - № 5. - 1988. - С. 120-128. 
10. Кондаков И.В. Архитектоника события // Мир психологии. - № 4(24). - 2000. С. 38-50.

11. Магомед-Эминов М.Ш. Личность и экстремальная жизненная ситуация // Вестн. Моск. ун-та. - Сер. 14. Психология. - № 4. - 1996. - С. 26-35.

12. Рубинштейн С.Л. Бытие и сознание. Человек и мир. - СПб.: Питер, 2003. - 512 с.

13. Рубинштейн С.Л. Основы общей психологии. - СПб.: Питер, 2005. - 713 с.

14. Сайко Э.В. Событийная жизнь человека в его событии // Мир психологии. № 4(24). - 2000. - С. 38-50.

15. Тхостов А.Ш., Степанович Д.А. Влияние кризисной жизненной ситуации на структуру самооценки // Вопросы психологии. - № 2. - 1987. - С. 128-133. 